\title{
Causes of death in patients with Huntington's disease and in unaffected first degree relatives
}

\author{
Sven Asger Sørensen, Kirsten Fenger
}

\begin{abstract}
Causes of death were examined from death certificates for 395 Danish subjects with Huntington's disease (HD) and for 282 unaffected sibs and compared with the causes of death in the general Danish population. For both the HD subjects and the sibs, pneumonia and cardiovascular diseases were the most frequent primary causes of death. Suicides accounted for $5 \cdot 6 \%$ of all deaths among the $\mathrm{HD}$ subjects and, unexpectedly, for $5 \cdot 3 \%$ among the sibs, some of whom may have been carriers of the HD gene. Both were significantly higher than the corresponding frequency of $2.7 \%$ in the general Danish population, but there was no evidence of differences in the age specific proportions for the HD subjects and for the sibs compared to the general population. Some accidents leading to death in the sibs may have been hidden suicides. The rate of cancer was low for the HD patients, being only $5 \cdot 3 \%$ compared with $31 \cdot 2 \%$ for the sibs. Neurological diseases were reported with an increased frequency in the HD patients compared to the general population, $6 \% \vee 1 \%$.
\end{abstract}

( $\mathcal{F}$ Med Genet 1992;29:911-14)

Huntington's disease is an autosomal dominant inherited neurodegenerative disorder that involves neurological and psychiatric symptoms. ${ }^{1}$ Involuntary choreic movements are the most characteristic symptoms but they may be slight or absent and other neurological symptoms may be present. The psychiatric symptoms include dementia, psychosis, and change in personality. The last may occur early but are rarely recognised in the early stages of the disease.

Onset is usually reported to be in the late third or early fourth decade of life, but is difficult to determine and may vary from early childhood to old age. The duration is 15 to 20 years from onset. The proportion of deaths attributed to suicide is often reported to be increased but the figures vary in different reports.

The purpose of the present paper is to report on the causes of death for HD subjects and their sibs who were not diagnosed as suffering from HD. Because of the late onset of $\mathrm{HD}$, asymptomatic persons who belong to an HD family and die at an early age may have been gene carriers. If their causes of death are unusual, it is to be expected that they will be different from the causes in the general population. Therefore, we have compared the cause of death of the sibs to that of the general population and also to that of the HD subjects.

\section{Material and methods}

The subjects were selected from fully updated families with Huntington's disease registered in the nationwide HD register at the Institute of Medical Genetics in Copenhagen. Copies of death certificates are systematically collected from the Danish National Board of Health for all registered persons who have died since 1943, and the present material comprised death certificates from a total of 677 dead subjects. Three hundred and ninety-five (184 females and 211 males) had been affected with HD. The diagnosis was based on clinical criteria and a positive family history of HD and was independent of the diagnosis given on the death certificate. The other 282 persons ( 119 females and 163 males) were first degree relatives of patients with Huntington's disease and had not, to our knowledge, been diagnosed as having Huntington's disease. Depending on their age at death, these persons therefore represent both normal homozygotes and nonmanifesting heterozygotes. The two sexes were not considered separately because the numbers for each cause of death were too small to show possible differences between the sexes.

The causes of death were obtained from the death certificates, on which usually at least two diagnoses are given: the primary cause of death and the underlying one. On many certificates contributory causes of death are also given. If only one cause of death was reported on a certificate, we marked that one both as the primary and as the underlying cause. On each certificate, the death is further reported as natural, suicide, homicide, accidental, or 'not stated'. We followed these notations even when we considered them uncertain.

We considered the primary, the underlying, and the contributory causes of death separately. As the official statistics on causes of death in Denmark are based on the underlying causes of death, we used these in a comparison between the proportions of the different causes of deaths among the subjects in the two samples with the corresponding proportions in the general Danish population. The latter were taken for the year 1981 as representative. ${ }^{2}$

A $\chi^{2}$ test was used to compare frequencies and Mantel-Haentzel $\chi^{2}$ test ${ }^{3}$ was used to compare two groups where age was a confounding factor. The significance level was $\mathbf{0} 05$. 
Table 1 Causes of death in HD; affected and at risk subjects.

\begin{tabular}{|c|c|c|c|c|c|c|c|c|c|c|c|c|}
\hline \multirow{3}{*}{$\begin{array}{l}\text { Causes of } \\
\text { death }\end{array}$} & \multicolumn{4}{|c|}{ Primary } & \multicolumn{4}{|c|}{ Underlying } & \multicolumn{4}{|c|}{ Primary, underlying, or contributory } \\
\hline & \multicolumn{2}{|c|}{ Affected } & \multicolumn{2}{|c|}{ At risk } & \multicolumn{2}{|c|}{ Affected } & \multicolumn{2}{|c|}{ At risk } & \multicolumn{2}{|c|}{ Affected } & \multicolumn{2}{|c|}{ At risk } \\
\hline & No & $\%$ & No & $\%$ & No & $\%$ & No & $\%$ & No & $\%$ & No & $\%$ \\
\hline $\begin{array}{l}\text { Pneumonia } \\
\text { Cardiovascular }\end{array}$ & 166 & $42 \cdot 0$ & 54 & $19 \cdot 1$ & 10 & $2 \cdot 5$ & 5 & $1 \cdot 8$ & 178 & $45 \cdot 1$ & 56 & $19 \cdot 9$ \\
\hline $\begin{array}{l}\text { diseases } \\
\text { Cachexia } \\
\text { Suicide } \\
\text { HD } \\
\text { Neurological diseases* } \\
\text { Accidents } \\
\text { Neoplasms (malignant) } \\
\text { Other } †\end{array}$ & $\begin{array}{r}69 \\
20 \\
21 \\
16 \\
4 \\
15 \\
15 \\
5 \\
79\end{array}$ & $\begin{array}{r}17 \cdot 5 \\
5 \cdot 1 \\
5 \cdot 3 \\
4 \cdot 1 \\
1 \cdot 0 \\
3 \cdot 8 \\
1 \cdot 3 \\
20 \cdot 0\end{array}$ & $\begin{array}{r}64 \\
15 \\
13 \\
0 \\
2 \\
20 \\
44 \\
70\end{array}$ & $\begin{array}{r}22 \cdot 7 \\
5 \cdot 3 \\
4 \cdot 6 \\
0 \\
0 \cdot 7 \\
7 \cdot 1 \\
15 \cdot 6 \\
24 \cdot 8\end{array}$ & $\begin{array}{r}48 \\
1 \\
22 \\
221 \\
25 \\
12 \\
13 \\
43\end{array}$ & $\begin{array}{r}12 \cdot 2 \\
0.3 \\
5 \cdot 6 \\
55.9 \\
6 \cdot 3 \\
3 \cdot 0 \\
3 \cdot 3 \\
10 \cdot 9\end{array}$ & $\begin{array}{r}91 \\
3 \\
12 \\
0 \\
5 \\
20 \\
88 \\
58\end{array}$ & $\begin{array}{r}32 \cdot 3 \\
1 \cdot 1 \\
4 \cdot 3 \\
0 \\
1 \cdot 8 \\
7 \cdot 1 \\
31 \cdot 2 \\
20 \cdot 6\end{array}$ & $\begin{array}{r}100 \\
44 \\
22 \\
301 \\
31 \\
23 \\
21 \\
156\end{array}$ & $\begin{array}{r}25 \cdot 3 \\
11 \cdot 1 \\
5 \cdot 6 \\
76 \cdot 2 \\
7 \cdot 8 \\
5 \cdot 8 \\
5 \cdot 3 \\
39 \cdot 5\end{array}$ & $\begin{array}{r}126 \\
20 \\
15 \\
0 \\
10 \\
20 \\
96 \\
161\end{array}$ & $\begin{array}{r}44 \cdot 7 \\
7 \cdot 1 \\
5 \cdot 3 \\
0 \\
3 \cdot 5 \\
7 \cdot 1 \\
34 \cdot 0 \\
57 \cdot 1\end{array}$ \\
\hline Total & 395 & 100 & 282 & 100 & 395 & 100 & 282 & 100 & - & - & - & - \\
\hline
\end{tabular}

Proportions in the general population: cardiovascular diseases $47.6 \%$; suicide $2.7 \%$; neurological diseases $0.9 \%$; neoplasms $25 \cdot 1 \%$.

* Apart from HD, subdural haematoma and cerebral haemorrhage.

$\dagger$ Includes gastrointestinal and urogenital diseases, respiratory diseases, infections, and unknown causes of death.

\section{Results}

The causes of death were grouped into nine main groups as shown in table 1 , where the distributions of the primary causes of death and the distributions of the underlying causes of death for the 395 patients with HD and the 282 unaffected sibs are given. This table also summarises any cause of death on the certificates; since each death certificate could have up to five causes of death, these numbers and percentages were not added.

For the HD patients the most frequent primary cause of death was pneumonia $(42.0 \%)$, and for the unaffected sibs there were two almost equally frequent primary causes, cardiovascular disease $(22.7 \%)$ and pneumonia $(19 \cdot 1 \%)$.

Naturally, HD was the leading underlying cause of death for the HD patients, but cardiovascular diseases were reported for $12 \cdot 2 \%$. For the sibs the corresponding frequency was $32.3 \%$, which with control for age was significantly lower than the frequency in the general Danish population $(47.6 \%, \mathrm{p}<0.001)$.

Table 2 shows the occurrence of suicides according to age among the $395 \mathrm{HD}$ patients, the 282 unaffected sibs, and the general Danish population in 1981. The proportion of deaths from suicide was $5.6 \%$ among the $\mathrm{HD}$ subjects and significantly higher than in the general Danish population $(2.7 \%, \mathrm{p}<0.01)$. The proportion among the sibs (5.3\%) was also significantly higher than in the general population $(\mathrm{p}<0.02)$.

Although the overall proportion of $5.6 \%$ in the HD subjects was higher than the $2 \cdot 7 \%$ for the general population, the proportions in the separate age groups below the age of 69 years were lower for the HD patients. Conversely, there were relatively few suicides in the general population for ages above 70 years, containing many deaths. However, the proportions in the separate age groups were rather uncertain because of the small numbers in the groups, as indicated by the wide $95 \%$ confidence intervals.

For the age groups 0 to 19,20 to 29 , and 50 to 59 the proportions of suicides were lower for the HD subjects than for the sibs. For the age groups 20 to 29 and 50 to 59 the proportions of deaths from suicide were higher for the sibs than for the general population.

Accidents as a primary cause of death occurred with a frequency of $3.8 \%$ in the HD patients and among the sibs with a frequency of $7 \cdot 1 \%$ (table 1); the frequencies were not significantly different. The types of accident are listed in table 3 from which it appears that the accidents in the HD subjects and in the sibs were of different types; 13 of the $23 \mathrm{HD}$ patients died from aspiration, but none of the sibs, but among the latter traffic accidents were more frequent. These traffic accidents were striking: six persons (males aged 18 to 53 years) were alone in a car and suddenly drove the car into the opposite lane where they crashed with a truck. Further, three were poisoned with carbon monoxide, one died after burns, and two were killed.

The proportion of all deaths attributed to cancer was $5.3 \%$ in the $395 \mathrm{HD}$ subjects (table 1). With control for age this frequency was strikingly lower $(p<0.0001)$ than that found for the general Danish population $(25 \cdot 1 \%)$, even though the latter figure only represented malignancy as the underlying cause of death.

Table 2 Suicides among 395 dead HD patients, 282 dead at risk subjects, and in the general Danish population (number and percentages with $95 \%$ confidence intervals).

\begin{tabular}{|c|c|c|c|c|c|c|c|c|c|}
\hline \multirow[b]{2}{*}{$\begin{array}{l}\text { Age group } \\
\text { (y) }\end{array}$} & \multicolumn{3}{|c|}{ HD patients } & \multicolumn{3}{|c|}{ At risk subjects } & \multicolumn{3}{|c|}{ Danish population (1981) } \\
\hline & $\begin{array}{l}\text { No of } \\
\text { deaths }\end{array}$ & $\begin{array}{l}\text { No of } \\
\text { suicides }\end{array}$ & $\%$ & $\begin{array}{l}\text { No of } \\
\text { deaths }\end{array}$ & $\begin{array}{l}\text { No of } \\
\text { suicides }\end{array}$ & $\%$ & $\begin{array}{l}\text { No of } \\
\text { deaths }\end{array}$ & $\begin{array}{l}\text { No of } \\
\text { suicides }\end{array}$ & $\%$ \\
\hline $\begin{array}{l}0-19 \\
20-29 \\
30-39 \\
40-49 \\
50-59 \\
60-69 \\
>70\end{array}$ & $\begin{array}{r}5 \\
6 \\
23 \\
70 \\
111 \\
109 \\
71\end{array}$ & $\begin{array}{l}0 \\
1 \\
4 \\
9 \\
4 \\
2 \\
2\end{array}$ & $\begin{array}{c}0(0-52) \\
16 \cdot 7(0-64) \\
17 \cdot 4(5-39) \\
12 \cdot 9(6-23) \\
3.6(1-9) \\
1.8(0-6) \\
2 \cdot 8(0-10)\end{array}$ & $\begin{array}{r}8 \\
14 \\
13 \\
16 \\
41 \\
56 \\
134\end{array}$ & $\begin{array}{l}1 \\
4 \\
1 \\
2 \\
5 \\
0 \\
2\end{array}$ & $\begin{array}{c}12 \cdot 5(0-53) \\
28 \cdot 6(8-58) \\
7 \cdot 7(0-36) \\
12.5(2-39) \\
12 \cdot 2(4-26) \\
0(0-6) \\
1.5(0-4)\end{array}$ & $\begin{array}{r}961 \\
642 \\
1022 \\
1900 \\
4710 \\
10267 \\
36613\end{array}$ & $\begin{array}{r}27 \\
166 \\
252 \\
273 \\
313 \\
261 \\
243\end{array}$ & $\begin{array}{l}2.8(2-4) \\
25.9(22-29) \\
24.7(22-27) \\
14.4(13-16) \\
6 \cdot 6(6-7) \\
2.5(2 \cdot 2-2 \cdot 8) \\
0.66(0.58-0.75)\end{array}$ \\
\hline Total & 395 & 22 & $5 \cdot 6$ & 282 & 15 & $5 \cdot 3$ & 56115 & 1535 & $2 \cdot 7$ \\
\hline
\end{tabular}


Table 3 Accidents among $23 \mathrm{HD}$ patients and 20 at risk subjects.

\begin{tabular}{lcc}
\hline Accident & HD & At risk subjects \\
\hline Aspiration & 13 & - \\
Burns & 3 & 1 \\
Crash with a vehicle in opposite & - & $6^{*}$ \\
lane & 2 & 5 \\
Other traffic accidents & 5 & 0 \\
Fall & - & 3 \\
Carbon monoxide poisoning & - & 2 \\
Homicide & - & 1 \\
Fall in an epileptic attack & - & 2 \\
Industrial accident & & \\
\hline
\end{tabular}

* All single drivers.

Neoplasms occurred as an underlying cause for $31.2 \%$ of the unaffected sibs, which with control for age was significantly higher than the $25.1 \%$ in the general population. However, this was only found for persons above 70 years of age.

Neurological diseases apart from HD, subdural haematoma, and cerebral haemorrhage occurred as the underlying cause of death strikingly more often among the HD subjects than in the general population $(6.3 \% v 0.9 \%$, $\mathrm{p}<0.001$ ) (table 1). The neurological diagnoses are listed in table 4. The diagnosis of $\mathrm{HD}$ was recorded on only four death certificates for the $31 \mathrm{HD}$ subjects with one (or two) neurological causes of death. The most frequent neurological diagnoses in the 27 certificates missing the diagnosis of HD were encephalitis (reported in 10), Parkinson's disease (five), and cryptogenic cerebral atrophy (five). The frequency of $1.8 \%$ observed for neurological disease as the underlying cause of death for the sibs was not significantly different from the frequency in the population $(0.9 \%)$.

\section{Discussion}

Causes of death for HD patients have been reported in various studies ${ }^{4-11}$ while suicide as the cause of death for at risk subjects has been mentioned in one study only. ${ }^{7}$

The determination of causes of death based on death certificates is subject to uncertainty. We found the diagnosis of HD given for only $76 \%$ of the patients for whom we had evidence that they did suffer from HD, although it was to be expected that almost all the death certificates would have this because there is space for three diagnoses besides the primary and the underlying causes of death. The significantly

Table 4 Neurological causes of death apart from HD for $31 \mathrm{HD}$ patients and 10 at risk subjects. Three of the $31 \mathrm{HD}$ patients had two diagnoses; only for four of the 31 was $H D$ reported on the death certificate.

\begin{tabular}{|c|c|c|c|c|c|c|}
\hline \multirow[b]{2}{*}{ Cause of death } & \multicolumn{2}{|c|}{ Primary } & \multicolumn{2}{|c|}{ Underlying } & \multicolumn{2}{|c|}{$\begin{array}{c}\text { Primary, } \\
\text { underlying, or } \\
\text { contributory }\end{array}$} \\
\hline & HD & At risk & HD & At risk & HD & At risk \\
\hline Hepatolenticular degeneration & - & - & 1 & - & 1 & - \\
\hline Werdnig-Hoffmann disease & - & - & - & 1 & - & 1 \\
\hline Encephalitis & 2 & - & 8 & 1 & 11 & 2 \\
\hline Familial cerebellar ataxia & - & - & 1 & - & 1 & - \\
\hline Multiple sclerosis & - & - & 3 & 1 & 3 & 1 \\
\hline Parkinson's disease & - & 1 & 5 & 1 & 5 & 2 \\
\hline Infantile cerebral paralysis & - & - & 2 & - & 2 & - \\
\hline Epilepsy & - & - & - & - & - & 3 \\
\hline Cerebral anoxia & - & 1 & - & 1 & - & 1 \\
\hline Progressive bulbar paralysis & - & - & 1 & - & 3 & - \\
\hline Senile chorea & 1 & - & - & - & 1 & - \\
\hline Encephalopathy & 1 & - & 4 & - & 7 & - \\
\hline
\end{tabular}

increased number of neurological diseases among HD patients also indicates that the diagnoses given on the certificates may be erroneous.

During the last 30 years, suicide has occurred in about $2.5 \%$ of all deaths in Denmark; thus, in this sample of $395 \mathrm{HD}$ subjects, suicide occurred twice as often as in the Danish population. The observed frequency of $5 \cdot 6 \%$ is similar to the frequency of $3.4 \%$ reported by Hayden $e t a l^{6}$ in South Africa, and to the $4 \%$ observed by Schoenfeld $e t a l$ in the USA, and close to the frequency of $5 \cdot 7 \%$ reported by Farrer, ${ }^{8}$ which is almost four times greater than the corresponding proportion for the USA Caucasian population. However, also in the USA, Haines and Conneally ${ }^{9}$ and Lanska et $a l^{10}$ found only $2 \%$ and $0.8 \%$, respectively, of suicides among HD patients. A similar low frequency of $1.6 \%$ was observed by Chiu and Alexander ${ }^{11}$ in Australia. These discrepancies may reflect variation in the suicide rates in different countries or the methods used for identifying suicides or both.

Our observed frequency of $5.6 \%$ represents a minimum, as only those cases who were reported in the death certificates as suicides are included in this number. There were more cases where the circumstances of death may have indicated suicide. About $40 \%$ of the patients who committed suicide were in their fourth decade indicating that this occurs most frequently shortly after the diagnosis has been established.

It was unexpected that the frequency of suicides among at risk subjects was similar to that of the HD patients and twice the frequency in the general population. One third of these suicides occurred before the age of 30 and $40 \%$ before the age of 40 , while the corresponding frequencies in the general population were $12.6 \%$ and $29.0 \%$, respectively. The numbers of at risk subjects in the different age groups were small and, consequently, conclusions are only tentative. Our finding of an increased suicide rate in first degree relatives is in contrast to the $1.8 \%$ reported by Farrer. ${ }^{8}$ These data were based on a questionnaire survey and, as pointed out by the author, suicides may have been underreported.

Some at risk subjects who died by accident may have committed suicide. Thus, three died of carbon monoxide poisoning and six in traffic accidents where they were alone in a car and suddenly drove the car into the opposite lane. Five of these latter persons were younger than 30 years, making it possible that at least some of them were gene carriers. The daughter of one of the young men developed juvenile HD after his death making it likely that he was a gene carrier but this does not prove that his death was a suicide and not an accident. If the former were true in this as well as in some of the other similar cases, it may suggest that carriers of the HD gene have a higher risk of committing suicide even before manifestation of the disease.

The high frequency of neurological diseases reported on the death certificates of $\mathrm{HD}$ 
patients compared to the general population is striking. In a case control study Lanska et al ${ }^{10}$ found a significantly increased number of "other diseases of the brain" and Schoenfeld et $a l$ reported $5.7 \%$ of "other neurological disease" as the primary cause of death, but did not give the corresponding frequency in the general population. An explanation of our finding may be erroneous diagnoses, as the majority of death certificates where a neurological disease was reported did not contain the diagnosis of $\mathrm{HD}$.

Even if all the diagnoses of cancer given in the death certificates of the HD patients were counted, the frequency of malignancies was much lower than in the general population, where cancer is only reported as a cause of death if it is the underlying cause. The lower frequency was not the result of the shorter life span of HD patients as we have corrected for this. A low proportion of deaths from cancer $(6 \%)$ was also noted by Haines and Conneally, by Schoenfeld et al $(4.5 \%)$, and by Farrer ${ }^{8}$ $(3.4 \%)$. The low occurrence of cancers among HD patients is not necessarily real. Typically, HD patients are cachectic during the last years of life and a malignancy may not be suspected unless necropsy is performed.

Divergences in the causes of death in at risk subjects in comparison to the general population may reflect the causes of death in gene carriers who have not yet manifested HD.

According to Conneally ${ }^{12}$ about one third of at risk subjects in the lower age groups are expected to be gene carriers who have not yet manifested HD. It is probable that the observed increased frequency of suicides and of the suspicious accidents among at risk persons is related to the HD gene, rendering the frequency of suicides among gene carriers even higher than the $5.6 \%$ we observed among persons manifesting HD. In this connection, it is of interest that Schoenfeld et al found the rate of suicide among persons with diagnosed and suspected Huntington's disease to be as high as $12 \cdot 7 \%$. Another possibility is that being at risk is in itself such a psychological burden to some persons that it results in suicide independent of carrier status.

This work was supported by The Danish Medical Council, Folmer og Ingeborg Lüttichaus Familiefond, Direktør Ib Henriksens Fond, and Toyota Fonden.

1 Hayden MR. Huntington's chorea. Berlin: Springer-Verlag, 1981

2 National Board of Health. Causes of death in the Kingdom of Denmark 1981. Copenhagen: Sundhedstyrelsen, 1983.

3 Armitage P, Berry G. Statistical methods in medical research. Oxford: Blackwell Scientific Publications, 1987.

4 Reed TE, Chandler JH. Huntington's chorea in Michigan. I. Demography and genetics. Am f Hum Genet 1958;10:201-25.

5 Wendt GG, Landzettel I, Stolth K. Krankenheitsdauer und Lebenserwartung bei der Huntingtonschen chorea. Arch Psych Nervenkr 1960;201:298-312.

6 Hayden MR, Erllich R, Parker H, Ferrera JJ. Social perspectives in Huntington's chorea. S Afr Med $\mathcal{f}$ 1980;58:201-3.

7 Schoenfeld M, Myers RH, Cupples LA, et al. Increased rate of suicide among patients with Huntington's disease. f Neurol Neurosurg Psychiatry 1984;47:1283-7.

8 Farrer LA. Suicide and attempted suicide in Huntington disease: implications for preclinical testing and persons at-risk. Am ₹ Med Genet 1986;24:305-11.

9 Haines JL, Conneally PM. Causes of death in Huntington disease as reported on death certificates. Genet Epidemiol 1986;3:417-23.

10 Lanska DJ, Lanska MJ, Lavine L, Schoenberg BS. Conditions associated with Huntington's disease at death. A case-control study. Arch Neurol 1988;45:878-80.

11 Chiu E, Alexander L. Causes of death in Huntington's disease. Med ₹ Austr 1982;20:153:

12 Conneally PM. Huntington disease: genetics and epidemiology. Am f Hum Genet 1984;36:506-26. 